\title{
A Conceptual Framework for Adaptive Storage Location Assignment Considering Order Characteristics ${ }^{1}$
}

\author{
Polina Görbe ${ }^{1}$, Tamás Bódis ${ }^{2}$, János Botzheim ${ }^{3}$ \\ ${ }^{1}$ Széchenyi István University, Audi Hungaria Faculty of Automotive Engineering, Departmant of Logistics and Forwarding, Győr, Hungary (ORCID: 0000-0001-8067- \\ 4432) \\ ${ }^{2}$ Széchenyi István University, Audi Hungaria Faculty of Automotive Engineering, Departmant of Logistics and Forwarding, Győr, Hungary (ORCID: 0000-0002- \\ 1255-8031) \\ ${ }^{3}$ Budapest University of Technology and Economics, Faculty of Mechanical Engineering, Departmant of Meachatronics, Optics and Mechanical Engineering \\ Informatics, Budapest, Hungary (ORCID: 0000-0002-7838-6148)
}

(Conference Date: 5-7 March 2020)

(DOI: 10.31590 /ejosat.araconf74)

ATIF/REFERENCE: Görbe, P., Bodis, T. \& Botzheim, J. (2020). A Conceptual Framework for Adaptive Storage Location Assignment Considering Order Characteristics. Avrupa Bilim ve Teknoloji Dergisi, (Special Issue), 610-614.

\begin{abstract}
Nowadays, the fragmented orders, the shrinking time windows, the special customer requirements, and the inventory reduction requirements are the biggest challenges in warehouse logistics and production supply. Research studies have already examined different type of order picking routing optimization and considered optimal storage location assignment (SLA). The several SLA solutions take into consideration several factors, however, these usually require the repositioning of the stored products.

Based on our industrial experiments there is a lack of industrial application and support of the systems to keep up the ideal SLA. The aim of this paper is to define a potential concept to keep up a nearly optimal SLA during order picking position replenishment with minimized number of time consuming and labor-intensive product repositioning tasks.
\end{abstract}

Keywords: Storage location assignment, Adaptive, Conceptual framework.

\section{Introduction}

Nowadays, the fragmented orders, the shrinking time windows, the special customer requirements, and the inventory reduction requirements are the biggest challenges in warehouse logistics and production supply. The order picking process needs to face with these challenges, which is the most labor intensive and costly part of the warehouse operations. While travelling time is approximately $50 \%$ of the whole picking time, the primary goal of the order picking process development is the routing optimization. The routing is strongly influenced by the storage location assignment and the layout design. The storage location assignment (SLA) methods allocate products to picking positions, which are visited by the pickers. The aim of the SLA optimization methods and algorithms is to support the effective order picking. The general Key Performance Indicator (KPI) of the order picking processes is the lead time which depends mostly on the routing distances (De Koster, Le-Duc, \& Roodbergen, 2007).

Koster et al. summarized the usually applied SLA policies, like random storage method, closest open location, dedicated storage strategy, full turnover storage, class-based storage, family grouping SLA strategy. The random storage method results high storage capacity utilization and increased travel distance, because the method selects position randomly. During the closest open location storage strategy, the warehouse worker or system can choose a free position during storing. The dedicated storage strategy is responsible for storing the products on fixed positions. In this strategy the space utilization is lower, because the storage position must be reserved all the time. The dedicated storage can support the order picking sequence, for example if the products have different weights and if stacking sequence is important. The full turnover storage considers the ordering intensity and the products turnover.

${ }^{1}$ This paper was presented at the International Conference on Access to Recent Advances in Engineering and Digitalization (ARACONF 2020). 
The class-based storage classifies the products and dedicates the positions for classes. One of the usually applied class-based strategy is when the products are classified based on Pareto's method, it focuses on the combination of the full turnover and the dedicated storage. The family grouping SLA strategy considers the relations of products based on ordered quantity, ordering frequency or product association (De Koster, Le-Duc, \& Roodbergen, 2007)

Gils et al. (2019) made a state-of-the-art research for the order picking problems, where the SLA-routing combinations are the most frequently published research. Most of the research studies focus on the picking travel distance, and therefore the picking time reduction with SLA optimization (Gils, Caris, Ramaekers, Braekers, \& de Koster, 2019). Quader et al. present a new model for orderpicking with bucket-brigades algorithm. This algorithm can be applied to multiple aisles warehouses to minimize the routing distances (Quader \& Castillo-Villar, 2018). Gils et al. (2018) compared some variations of warehousing decision fields: SLA and order batching; SLA and picker routing; SLA and zone picking; order batching and picker routing; order batching and zone picking; zone picking and picker routing. This paper explicitly analyzed and statistically proved the relations among storage, batching, zoning, and routing (Gils, Ramaekers, Braekers, Depaire, \& Caris, 2018). Dijkstra et al. focused on the combined effects of routing methods and SLA. They presented formulas for the average route length in the case of any SLA for four common routing methods, like Return routing, Largest-gap routing, S-shape routing and Midpoint routing. In addition, they presented a dynamic programming approach. This approach determines SLA, using the route length formulas and optimality properties (Dijkstra \& Roodbergen, 2017).

Some author writes about different approach for algorithmic SLA optimization and some of them consider the repositioning of the products in the warehouse.

Manzini et al. classified the products and examined the products' „life's cycles” effect on the picking process (Manzini, Accorsi, Gamberi, \& Penazzi, 2015). Product features, like temperature sensitivity, packaging type and weight are important factors during SLA optimization. Accorsi et al. examined the storage possibilities and repositioning requirements of temperature-sensitive products. They consider external environmental factors also to store the products on safe positions, for example the seasons change, different temperature circumstances next to storage walls and windows (Accorsi, Baruffaldi, \& Manzini, 2018). Žulj et al. optimized the SLA and the picking-routing considering the product parameters for the picking. During the picking task, for example the heavier products must be collected earlier than lighter products, thus protecting the products (Žulj, Glock, Grosse, \& Schneider, 2018).

While orders characteristics are one of the most influencing aspects of the SLA, Micale et al. considered the orders for defining the picking positions for the articles (Micale, La Fata, \& La Scalia, 2019). Furthermore, the demand fluctuation makes the periodic SLA optimization necessary, to keep up the order picking efficiency in the case of the changing demands. The right time period for the repositioning is generally unique warehouse by warehouse. Wang et al. focused on when to reassign the storage locations for cost reduction depending on the demand fluctuation (Wang \& Zhang, 2019).

However, the repositioning of the items is labor intensive, it needs warehouse operation shutdown or overtime to load the products from their current location for the updated ideal location. Because of its labor-intensive nature research works have been made to optimize the process of warehouse reorganization in order to minimize the time loss. Because of the complexity of the problems, Héctor et al. suggested some heuristics for defining the right processes and the necessary amount of repositioning (Carlo \& Giraldo, 2012). However, it still requires overtime or free time slot from the warehouse operations.

While applying the updated SLA usually requires some time consuming and labor-intensive product repositioning, this paper focuses on a potential concept to keep up the nearly optimal SLA during picking position replenishment without repositioning. Naturally there are possible cases when repositioning is necessary because of strong seasonality and dramatic decreases of the demands.

\section{Conceptual Framework for Adaptive Storage Location Assignment}

Because of the increasing effects of the fluctuating demands and the changing order characteristics, we needed to realize that the warehouses should have any digitalized support SLA optimization to be able to adjust to the changing requirements and to keep up the order picking efficiency. We believe that this solution should be integrated into the everyday processes and the warehousing system mostly should be able to keep up the efficiency by itself with the right algorithmic support. It can minimize the extra workloads which are independent from the orders and therefore not directly value making tasks, for example repositioning every item based on the new SLA.

The aim of our Adaptive Storage Location Assignment (ASLA) conceptual framework is to optimize the SLA periodically based on the actual circumstances, adapt and apply the results for the daily operations. The defined goals require from the ASLA to be integrated to the IT system of the warehouse.

The integration can be done by an interfaced external module which is connected to the Warehouse Management System (WMS) and to the Enterprise Resource Planning (ERP) system. (Fig 1.) Furthermore, the optimization algorithm can be an internal part of the WMS. The integration let us be able to reach the necessary inputs and supports the adaptation of the actualized SLA. The WMS will be able to apply the actualized ideal SLA in the storage system during the order picking position replenishments and the minimized number of repositions tasks. 


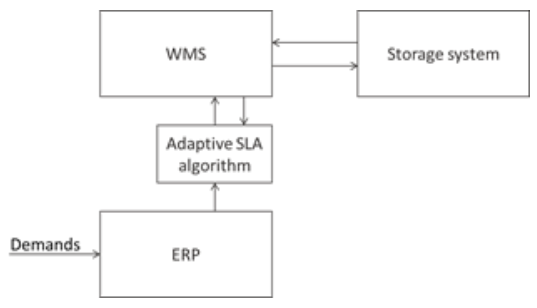

Fig. 1 ASLA integration

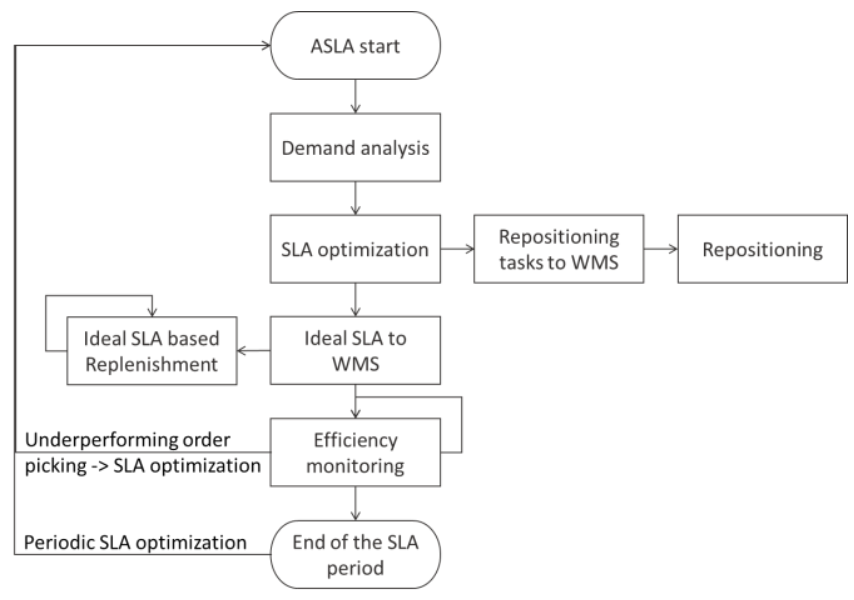

Fig. 2 ASLA workflow

The ASLA workflow (Fig. 2) starts with the demand analysis, when based on the previously defined time period the booked orders from the ERP will be investigated and classified. The results of this step are:

- Updated ordering frequency parameter of the products which shows, how often the products are ordered. It neglects the ordered quantity.

- Updated product parameters (for example packaging, product groups etc.)

- Updated family grouping parameters, to highlight which products should be allocated near to each other.

- The defined number of sample orders which contain the generalized characteristics of the orders. These sample orders will be used for evaluating the possible SLA solutions during the optimization.

- The SLA optimization algorithm defines the ideal SLA based on the actual ordering frequencies, product parameters, and family grouping parameters. The algorithm results in:

- ideal SLA for adaptation,

- minimized number of repositioning tasks.

The ideal SLA is adapted and continuously applied by the WMS. When replenishment of a product is necessary on its order picking position, then the replenishment will apply the updated SLA and find a new picking position for the product near to the ideal SLA based position. While the ideal picking position possibly won't be free, this solution will approximate to the optimal SLA replenishment by replenishment continuously without extra tasks and workloads.

Repositioning of products on the picking positions without replenishment should be minimized because of its extra workload requirements, but it is sometimes not neglectable. When the ordering frequency of the product is dramatically changed since the previous optimization, then it can be more effective to move immediately near to the new SLA position than waiting for the replenishment.

As an optional step of the workflow, the efficiency of the order picking process continuously should be monitored. When it is already underperforming because of the ineffective SLA, then the ASLA workflow should be repeated. The efficiency can be monitored for example based on picking lead times of order categories.

The periodic cycle of the ASLA makes the solution possible to continuously keep up the order picking efficiency. The time period should be defined individually for warehouses based on the order characteristics. When any dramatic change happens during the period, then the time period is stopped and the ASLA workflow is repeated based on the efficiency monitoring.

\section{Algorithm Concept}

The SLA can be generalized as a known Quadratic Assignment Problem (QAP). In a general point of view there are a set of $n$ facilities and a set of $n$ locations. For each pair of locations, a distance is specified and for each pair of facilities a weight is defined. The QAP algorithms are responsible for assigning all facilities to different locations with minimized distances which are multiplied by 
the defined weights. In the case of SLA, the facilities are products and the locations are order picking positions. The distances between the positions can be defined based on the warehouse layout. The weights of the product pairs should be defined based on the order characteristics. If pair of products are ordered together frequently, then the weight should be higher (Koopmans \& Beckmann, 1957).

While QAP is known to be strongly NP-hard combinatorial problem (Sahni \& Gonzalez, T., 1967), the number of possible combinations can be high and because of the operational application we have short possible time window for running, we offer meta heuristics and evolutionary algorithms for the given problem. While Chmiel (2019) highlighted based on state-of-the-art research that evolutionary or similar solutions for solving the QAP have still not been found, defining evolutionary algorithm for QAP based SLA optimization algorithm would be a novel result (Chmiel, 2019).

Based on our previous experiences Bacterial Memetic Algorithm (BMA) can be a possible algorithm for solving the ASLA problem. It has already been successfully applied for several combinatorial optimization problems because of its fast convergence speed. The applied local search operator helps the algorithm quicker converge to the global optimum. The BMA algorithm operates in four steps. The first step is to create an initial population with Nind individuals (bacteria), each bacterium represents a solution to the original problem. This can be done randomly, or some further rules can be defined. Next, bacterial mutation, local search methods, and gene transfer operator are applied in the bacterium population. These 3 operators are repeated while the stopping condition is achieved. The stopping condition is usually given by a predefined maximum number of generations (Ngen) (Botzheim, Cabrita, Koczy, \& Ruano, 2009), (Földesi, Botzheim, \& Kóczy, 2011), (Bódis \& Botzheim, 2018).

The proposed BMA algorithm is offered for optimizing i product allocation on the $\mathrm{p}$ order picking positions, when $\mathrm{i}=\mathrm{p}$. Each bacterium represents a possible allocation of the products on the order picking positions. The length of an individual is equal to the number of order picking positions $(\mathrm{p})$ because every picking position has to handle a product. There can be further possible cases when $\mathrm{i}>\mathrm{p}$ and $\mathrm{i}<\mathrm{p}$.

The individuals should be evaluated based on 2 possible values. The summary of the weighted distances should be minimized, and the defined generalized order picking lists' lead time should be minimized. The 2 values should be merged and minimized.

Definition of the appropriate bacterial mutation, local search, and gene transfer operators is the next step of the particular research, which will be evaluated based on industrially relevant inputs.

\section{Conclusion}

This paper highlighted a short state-of-the-art research of warehousing storage location assignment (SLA), where most of the research works concerned with repositioning of the products after optimization. Repositioning of the items is very labor intensive. It needs warehouse operation shutdown or overtime to load the products from their current location for the updated ideal location. Research has been made to optimize the process of warehouse reorganization to minimize the time loss.

This paper defined a potential concept to keep up the nearly optimal SLA during picking position replenishment without process independent repositioning. Naturally there are possible cases when repositioning is necessary, but the proposed concept can help us to minimize these movements. If the warehouse does the order picking position replenishment based on the actualized SLA, the warehouse can save time and eliminate extra workloads.

The next possible step of the research is to define BMA operators and evaluate them on industrially relevant inputs. The first period of this research focuses on the cases when the number of the products and positions are the same. In the future we would like to extend it for industrially more relevant cases when the number of the products and positions are not equal.

\section{Acknowledgment}

P. Görbe and T. Bódis acknowledge the financial support of this research by the Project EFOP-3.6.1-16-2016-00017. Internationalisation, initiatives to establish a new source of researchers and graduates, and development of knowledge and technological transfer as instruments of intelligent specialisations at Széchenyi István University.

J. Botzheim was supported by the János Bolyai Research Scholarship of the Hungarian Academy of Sciences.

\section{Reference}

Accorsi, R., Baruffaldi, G., \& Manzini, R. (2018). Picking efficiency and stock safety: A bi-objective storage assignment policy for temperature-sensitive products. Computers \& Industrial Engineering Volume 115, 240-252.

Bódis, T., \& Botzheim, J. (2018). Bacterial Memetic Algorithms For Order Picking Routing Problem With Loading Constraints. Expert Systems with Applications, 105, 196-220.

Botzheim, J., Cabrita, C., Koczy, L. T., \& Ruano, A. (2009). Fuzzy rule extraction by bacterial memetic algorithms. International Journal of Intelligent Systems, 24(3), 312-339.

Carlo, H. J., \& Giraldo, G. E. (2012). Toward perpetually organized unit-load warehouses. Computers \& Industrial Engeneering Volume 63, 1003-1012.

Chmiel, W. (2019). Evolutionary algorithm using conditional expectation value for quadratic assignment problem. Swarm and Evolutionary Computation, 46, 1-27. 
De Koster, R., Le-Duc, T., \& Roodbergen, K. J. (2007). Design and control of warehouse order picking: A literature review. European Journal of Operational Research, 182, 481-501.

Dijkstra, A. S., \& Roodbergen, K. J. (2017). Exact route-length formulas and a storage location assignment heuristic for picker-toparts warehouses. Transportation Research Part E, 38-59.

Földesi, P., Botzheim, J., \& Kóczy, L. T. (2011). EUGENIC BACTERIAL MEMETIC ALGORITHM FOR FUZZY ROAD TRANSPORT TRAVELING SALESMAN PROBLEM. International Journal of Innovative Computing, 5(2775-2798), 7.

Gils, T. v., Caris, A., Ramaekers, K., Braekers, K., \& de Koster, R. B. (2019). Designing efficient order picking systems: The effect of real-life features on the relationship among planning problems. Transportation Research Part E 125, 47-73.

Gils, T. v., Ramaekers, K., Braekers, K., Depaire, B., \& Caris, A. (2018). Increasing order picking efficiency by integrating storage, batching, zone picking, and routing policy decisions. International Journal pf Production Economics, 243-261.

Koopmans, T. C., \& Beckmann, M. (1957). Assignment Problems and the Location of Economic Activities. Econometrica, 25(1), 5376.

Manzini, R., Accorsi, R., Gamberi, M., \& Penazzi, S. (2015). Modeling class-based storage assignment over life cycle picking patterns. Int. J. Production Economics Volume 170, Part C, 790-800.

Micale, R., La Fata, C., \& La Scalia, G. (2019). A combined interval-valued ELECTRE TRI and TOPSIS approach for solving the storage location assignment problem. Computers \& Industrial Engineering 135, 199-210.

Quader, S., \& Castillo-Villar, K. K. (2018). Design of an enhanced multi-aisle order-picking system considering storage assignments and routing heuristics. Robotics and Computer-Integrated Manufacturing 50, 13-29.

Sahni, S., \& Gonzalez, T. (1967). P-Complete Approximation Problems. Journal of the ACM (JACM), 23(3), 555-565.

Wang, M., \& Zhang, R.-Q. (2019). A dynamic programming approach for storage location assignment planning problem. Procedia CIRP 83, 513-516.

Žulj, I., Glock, C. H., Grosse, E. H., \& Schneider, M. (2018). Picker routing and storage-assignment strategies for precedenceconstrained order picking. Computers \& Industrial Engineering Volume 123, 338-347. 